\title{
CORRIGENDUM
}

\section{Safety, tolerability and sustained weight loss over 2 years with the once-daily human GLP-1 analogue, liraglutide}

A Astrup, R Carraro, N Finer, A Harper, M Kunesova, MEJ Lean, L Niskanen, MF Rasmussen, A Rissanen, S Rössner, MJ Savolainen and L Van Gaal on behalf of the NN8022-1807 Investigators

International Journal of Obesity (2012) 36, 890; doi:10.1038/ijo.2011.203

Correction to: International Journal of Obesity advance online publication 16 August 2011; doi: 10.1038/ijo.2011.158

Since the publication of this article the authors have noticed an error in one of the figures (Figure 4A). This error has now been rectified and the corrected article appears in this issue. The html and online pdf versions have also been rectified and now carry the correct figure.

The authors would like to apologize for this error. 